\title{
A novel optimization harmonic elimination technique for cascaded multilevel inverter
}

\author{
Ezzidin Hassan Aboadla ${ }^{1}$, Sheroz Khan ${ }^{2}$, Mohamed H. Habaebi ${ }^{3}$, Teddy Surya Gunawan ${ }^{4}$, \\ Belal A. Hamida ${ }^{5}$, Mashkuri Bin Yaacob ${ }^{6}$, Ali Aboadla ${ }^{7}$ \\ 1,2,3,4,5,6 Department of Electrical and Computer Engineering, International Islamic University Malaysia, Malaysia \\ ${ }^{1,7}$ Department of Electrical and Electronics Engineering, Higher Institute of Science and Technology, Al-Zahra, Libya
}

\begin{tabular}{l}
\hline \hline Article Info \\
\hline Article history: \\
Received Dec 14, 2018 \\
Revised Feb 1, 2019 \\
Accepted Mar 5, 2019 \\
\hline Keywords: \\
Cascaded Multilevel Inverter \\
Duty cycle \\
Optimization technique \\
Selective Harmonic Elimination \\
Switching angles
\end{tabular}

\begin{abstract}
The main goal of utilizing Selective Harmonic Elimination (SHE) techniques in Multilevel Inverters (MLI) is to produce a high-quality output voltage signal with a minimum Total Harmonic Distortion (THD). By calculating $N$ switching angles, SHE technique can eliminate $(N-1)$ low order odd harmonics of the output voltage waveform. To optimized and obtained these switching angles, $N$ of nonlinear equations should be solved using a numerical method. Modulation index $(m)$ and duty cycle play a big role in selective harmonic elimination technique to obtain a minimum harmonic distortion and desired fundamental component voltage. In this paper, a novel Optimization Harmonic Elimination Technique (OHET) based on SHE scheme is proposed to re-mitigate Total Harmonic Distortion. The performance of seven-level H-bridge cascade inverter is evaluated using PSIM and validated experimentally by developing a purposely built microcontroller-based printed circuit board.
\end{abstract}

Copyright (c) 2019 Institute of Advanced Engineering and Science. All rights reserved.

\section{Corresponding Author:}

Ezzidin Hassan Aboadla,

Department of Electrical and Computer Engineering,

International Islamic University Malaysia,

P.O. Box 10, 50728 Kuala Lumpur, Malaysia

Email: aboadlla@gmail.com

\section{INTRODUCTION}

The rapid development of power electronic devices, better be called renewable energy electronics, has effectively contributed to find more utilization of renewable energy applications in wind and solar energy. DC/AC inverter has become more interesting for interfacing between renewable sources and the grid in order to invert the energy from DC to AC form [1-4]. Recently, Multilevel Inverters (MLIs) have become more popular in photovoltaic (PV) applications. These topologies are mainly utilized in high and medium power practical applications because of their capacity to generate a high-quality output signal with decreased switch loss by power switches employed [5, 6]. However, multilevel inverters include a number of cells of power semiconductor devices which suffer from some challenging issues in more complex topologies [7].

By increasing the number of levels the quality of the output wave shape improves with minimizing THD and making the output closer to a sinusoidal signal [8]. The suitable topology for medium and high power application is Cascaded full bridge multilevel inverter. The control circuit of this kind of inverters is simpler than other topologies [9]. Also, it can be easily extended to higher levels to produce high power by adding more units of $\mathrm{H}$-Bridge on the series connection. The main disadvantage of the cascade multilevel inverter is the large number of DC voltage sources wanted to feed all the H-bridge cells, and hence all these DC sources have to be isolated [10]. However, it can reduce the switching losses and eliminate the effect of harmonic spikes from the output waveform with higher efficiency [11]. The THD of the multilevel inverters output voltage must be a minimum value. 
Several modulation techniques have been used to control the operation of the switching devices, the fundamental amplitude of the output waveform and THD dependent on the switching frequency [12, 13]. For high switching frequency methods, Sinusoidal Pulse Width Modulation is a more suitable scheme [14]. This technique is not able to cancel the low order odd harmonics completely from the output voltage signal, also with using high switching frequency in high power application, the switching losses lead to major concern from the total multilevel converters losses $[15,16]$. Selective Harmonic Elimination scheme is utilized for low switching frequency multilevel converters application. This technique is used to eliminate the low order odd harmonics from the output voltage signals by computing a set of identified nonlinear equations [17, 18].

Modulation index and Duty cycle are significant parameters affecting negatively or positively on the THD [19]. In this paper, optimization harmonic elimination method for cascaded multilevel inverters is investigated based on SHE technique. The performance of the proposed technique on the THD and the output voltage of cascaded seven-level inverter is evaluated by PSIM software and validated experimentally.

\section{CASCADED MULTILEVEL INVERTER}

Cascaded multilevel converters have added more attention to their utility in industrial and renewable energy electronics, mainly attributed to its modularity, symmetrical structure, and simplicity of control circuit. Series of full bridge units are connected with each isolated DC voltage source for each in cascade topology in order to generate a high quality and high power output voltage waveform [20-23]. Therefore, the maximum output voltage level of the cascaded multilevel inverter corresponding to the sum of the output voltage of all active $\mathrm{H}$-Bridges and the number of levels can be calculated by:

$$
l=2 s+1
$$

Where: $l$ is the number of levels, and $s$ is the number of input DC voltage sources.

A typical topology of a seven-level cascaded inverter contains three units of H-Bridge inverters tied in series with three isolated DC voltage sources as depicted in Figure 1. Each unit can produce three levels in its output waveform, $(+\mathrm{Vdc}, 0$, and $-\mathrm{Vdc})$. The output voltage waveform of a seven-level cascaded inverter is presented in Figure 2.

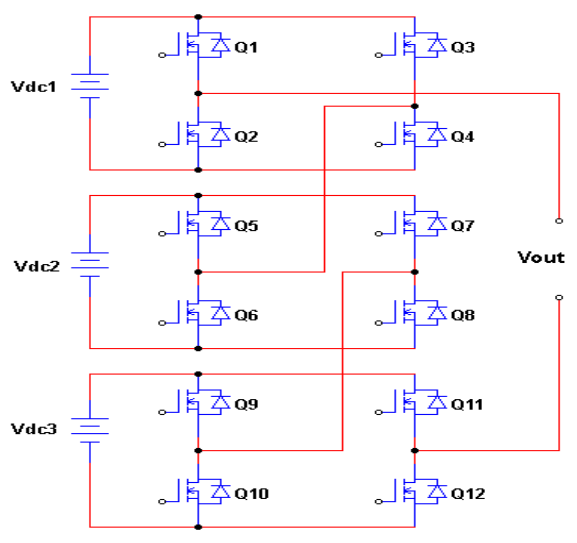

Figure 1. Single phase cascaded seven-level inverter

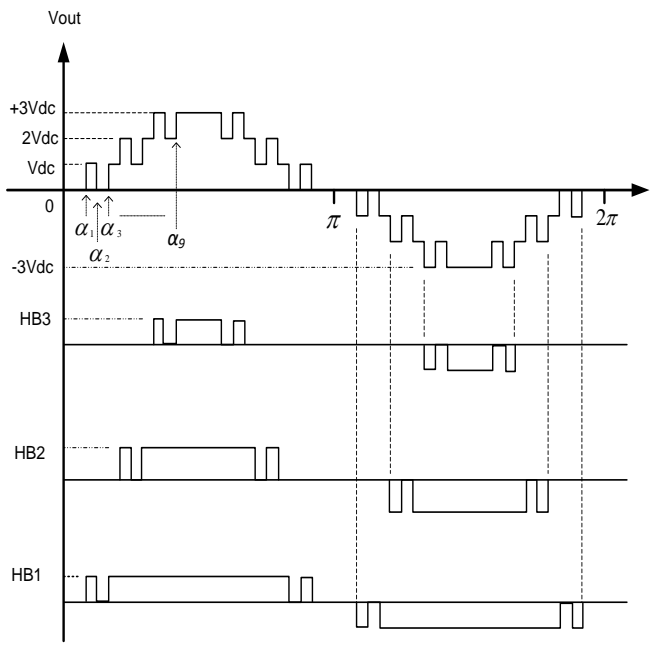

Figure 2. The output voltage signal of 7-level cascaded inverter and the control signal of all $\mathrm{H}$-Bridge units

\section{SELECTIVE HARMONIC ELIMINATION METHOD}

SHE technique is a mathematical (programmable) technique applied to generate a digital switching signal for multilevel inverters. The main target of this method is to remove selected undesirable low order odd harmonics from the output multilevel inverter waveform while using a low pass filter to mitigate the highest order harmonics. In addition, it works with low switching frequency, which will minimize the total switching losses without compromising the quality produced voltage. Also, it has the ability to leave tripling 
harmonics unremoved because it can remove by line to line voltage in three-phase inverter system [24-26]. Solving a nonlinear equations system in order to calculate the switching angles namely, $\left(\alpha_{1}, \alpha_{2}, \ldots \ldots, \alpha_{N}\right)$ in the range between 0 and $90^{\circ}$. By setting the best solution of these switching angles under suitable condition of modulation index $(\mathrm{m})$ in the range of $0<\mathrm{m}<1$, the unwanted low order odd harmonics can be removed from the output signal. Fourier series expansion can be utilized to obtain the amplitude of any odd harmonic of the multilevel inverter output signals which can be given by:

$$
V_{n}=\frac{4 S V_{d c}}{n \pi}\left[\cos \left(n \alpha_{1}\right)+\cos \left(n \alpha_{2}\right)+\cdots+\cos \left(n \alpha_{S}\right)\right]
$$

Where: s shows the number of input DC voltage sources, Vn; the amplitude of odd harmonics, n; the odd harmonics number, Vdc; input DC voltage source, $\mathrm{N}$; the number of switching angles, $\alpha \mathrm{N}$; switching angles that conditional by:

$$
0<\alpha_{1}<\alpha_{2}<\cdots<\alpha_{k}<\frac{\pi}{2}
$$

The major challenge in SHE techniques is that of solving a number of nonlinear equations to obtain a solution of unknown switching angles. Several numerical methods applied to SHE technique such as Generic-Algorithm (GA) [27], Newton-Raphson (NR) [28], Particle swarm optimization (PSO) [29]. However, the big problem of solving nonlinear equations with SHE technique in the large number of switching angles, because it makes the algorithm much more complicated. Also, by increasing the number of switching angles, the probability of getting the optimum solution of the switching angles is getting reduced $[30,31]$.

\section{OHET TECHNIQUE}

To generate a high-quality output signal as close to sinusoidal as possible from the multilevel inverters with the lowest THD, OHET has utilized SHE method to eliminate specific low order odd harmonics by modulating three parameters, that is, Number of pulses per quarter cycle, Modulation index, and Duty cycle. This method begins by determining the number of pulses in the quarter cycle of the output voltage signal to identify the switching angles which will use to eliminate the unwanted low order harmonics. Using a numerical method of Newton-Raphson identified nonlinear equations are solved to determine the desired switching angles and mitigating the undesirable odd harmonics under different values of modulation indices.

In this paper, the power switches in each unit of H-Bridge inverter will switch three times per cycle that means the output voltage signal has nine switching angles. Hence, the undesirable low order odd harmonics which can be eliminated equals to eight selected harmonics. The Fourier expansion of the harmonic component voltage using the SHE schemes for this technique is given by:

$$
\mathrm{V}_{\mathrm{n}}=\frac{4 \mathrm{SV}_{\mathrm{dc}}}{\mathrm{n} \pi}\left[\sum_{\mathrm{k}=1}^{\mathrm{N}} \cos (\mathrm{n} \alpha \mathrm{k}) \pm \sum_{\mathrm{k}=1}^{\mathrm{N}} \cos (\mathrm{n} \alpha \mathrm{k}) \pm \ldots \sum_{\mathrm{k}=1}^{\mathrm{N}} \cos (\mathrm{n} \alpha \mathrm{k})\right]
$$

There are nine nonlinear equations used to eliminate eight low odd harmonics (3rd, 5th, 7th, 9th, 11 th, 13th, 15th, 17th harmonics) by making its amplitude equal zero as under:

$$
\begin{aligned}
& \left(\cos \alpha_{1}-\cos \alpha_{2}+\cos \alpha_{3}\right)+\left(\cos \alpha_{4}-\cos \alpha_{5}+\cos \alpha_{6}\right)+\left(\cos \alpha_{7}-\cos \alpha_{8}+\cos \alpha_{9}\right)=m \\
& \left(\cos 3 \alpha_{1}-\cos 3 \alpha_{2}+\cos 3 \alpha_{3}\right)+\left(\cos 3 \alpha_{4}-\cos 3 \alpha_{5}+\cos 3 \alpha_{6}\right)+\left(\cos 3 \alpha_{7}-\cos 3 \alpha_{8}+\cos 3 \alpha_{9}\right)=0 \\
& \left(\cos 5 \alpha_{1}-\cos 5 \alpha_{2}+\cos 5 \alpha_{3}\right)+\left(\cos 5 \alpha_{4}-\cos 5 \alpha_{5}+\cos 5 \alpha_{6}\right)+\left(\cos 5 \alpha_{7}-\cos 5 \alpha_{8}+\cos 5 \alpha_{9}\right)=0 \\
& \left(\cos 13 \alpha_{1}-\cos 13 \alpha_{2}+\cos 13 \alpha_{3}\right)+\left(\cos 13 \alpha_{4}-\cos 13 \alpha_{5}+\cos 13 \alpha_{6}\right)+\left(\cos 13 \alpha_{7}-\cos 13 \alpha_{8}+\cos 13 \alpha_{9}\right)=0 \\
& \left(\cos 15 \alpha_{1}-\cos 15 \alpha_{2}+\cos 15 \alpha_{3}\right)+\left(\cos 15 \alpha_{4}-\cos 15 \alpha_{5}+\cos 15 \alpha_{6}\right)+\left(\cos 15 \alpha_{7}-\cos 15 \alpha_{8}+\cos 15 \alpha_{9}\right)=0 \\
& \left(\cos 17 \alpha_{1}-\cos 17 \alpha_{2}+\cos 17 \alpha_{3}\right)+\left(\cos 17 \alpha_{4}-\cos 17 \alpha_{5}+\cos 17 \alpha_{6}\right)+\left(\cos 17 \alpha_{7}-\cos 17 \alpha_{8}+\cos 17 \alpha_{9}\right)=0 \\
& m=\frac{\pi V_{1}}{4 s V_{d c}}
\end{aligned}
$$

Where: $\mathrm{m}$ is the modulation index and $V_{l}$ is the amplitude of the fundamental component of the output voltage.

The calculated switching angles $\left(\alpha_{1}, \alpha_{2}, \ldots, \alpha_{9}\right)$ must satisfy the conditions in (3). In this proposed technique, the Newton-Raphson method has been used to determine nine nonlinear equations. By changing the value of modulation index in the range between $0<\mathrm{m}<1$ can control the amplitude of the first harmonic, 
while desired unwanted harmonics can be removed from the output signal by making its amplitude equal zero. Each value of modulation index will get a new solution of the switching angles. The best result of switching angles, which achieve a minimum THD which is calculated by:

$$
T H D=\frac{\sqrt{\sum_{n=2}^{\infty}\left(\frac{1}{n} \sum_{k=1}^{N} \cos \left(n \alpha_{k}\right)\right)^{2}}}{\sum_{k=1}^{N} \cos \left(\alpha_{k}\right)}
$$

By changing the position of the switching angle (i.e. $\alpha \_1$ ), the duty cycle of the pulse will change affecting value of THD accordingly. In this paper, the duty cycle technique is used to optimize the solution of the switching angles and re-mitigate THD and improve the quality of the multilevel inverter output waveform. With delaying the optimal solution of the switching angles $\left(\alpha_{1}, \alpha_{2}, \ldots \ldots, \alpha_{9}\right)$ which are obtained in the previous step from the value of $(\Delta \alpha)$ as shown in Figure 3, a new value of THD is obtained. This new value of THD may be rise or fall depending on the position of switching angles. To identify the optimum new position of the switching angles that can achieve a new and lowest value of THD with the highest amplitude of the fundamental component of output voltage, OHET is used by subtraction the factor $(\Delta \alpha)$ from the value of switching angles $\left(\alpha_{1}, \alpha_{2}, \ldots ., \alpha_{9}\right)$ as given below:

$$
\begin{aligned}
& \alpha_{1}=\alpha_{1}-\Delta \alpha \\
& \alpha_{2}=\alpha_{2}-\Delta \alpha \\
& \alpha_{9}=\alpha_{9}-\Delta \alpha
\end{aligned}
$$

Where: $\Delta \alpha$ in radians and the new switching angles result must be satisfied the condition in (3).

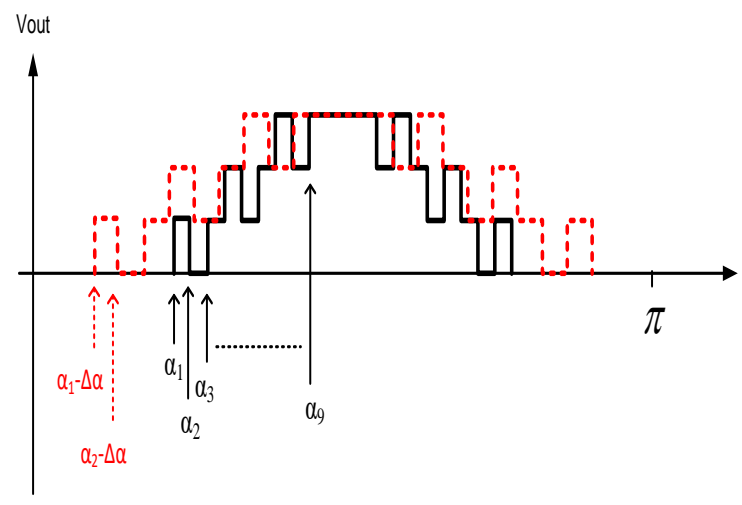

Figure 3. Duty cycle technique

\section{SIMULATION RESULTS}

Seven-level cascaded inverter has been used to verify the performance of OHET technique through PSIM simulation. With using SHE method for seven-level inverter, there are nine switching angles $\left(\alpha_{1}\right.$ to $\left.\alpha_{9}\right)$ in the quarter cycle signal which are used to eliminate eight low order harmonics $\left(5^{\text {th }}, 7^{\text {th }}, 11^{\text {th }}, 13^{\text {th }}, 17^{\text {th }}, 19^{\text {th }}\right.$, $21^{\text {th }}$, and $25^{\text {th }}$ ) without triplen harmonics from the output voltage waveform of the seven-level inverter. Newton-Raphson (NR) method has been used to calculate these unknown angles under different values of modulation indices. Figure 4 shows the solution of switching angles versus different values of modulation index. Using these results of switching angles to calculate THD by (7) to identify the best solution which, achieve the lowest THD.

Figure 4 shows the solution of unknown switching angles achieved in the range of modulation index between 0.6 to 1.0. However, the optimum solution is achieved with the lowest THD as depicted in Figure 5 at $\mathrm{m}=1.0$ with $\mathrm{THD}=11.49 \%$ (calculating) is given in Table 1 . 


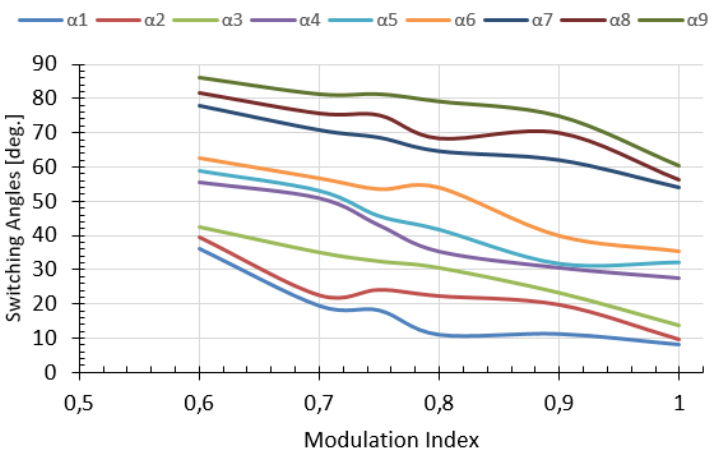

Figure 4. Switching angles versus modulation index

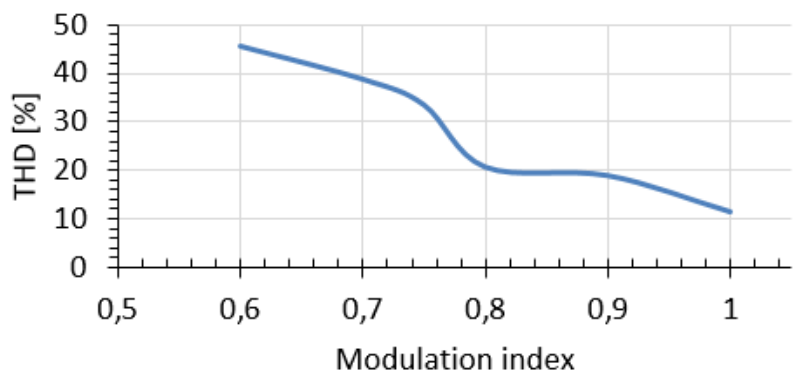

Figure 5. THD against modulation index

Table 1 . The result of switching angles at $m=1.0$

\begin{tabular}{cccccccccc}
\hline S. angles & $\alpha 1$ & $\alpha 2$ & $\alpha 3$ & $\alpha 4$ & $\alpha 5$ & $\alpha 6$ & $\alpha 7$ & $\alpha 8$ & $\alpha 9$ \\
\hline Degree & 8.043 & 9.453 & 13.616 & 27.610 & 32.251 & 35.505 & 54.087 & 56.202 & 60.278 \\
Radian & 0.140 & 0.165 & 0.237 & 0.481 & 0.562 & 0.619 & 0.944 & 0.980 & 1.052 \\
\hline
\end{tabular}

These angles are used to operate the inverter switches. The output voltage waveform of the seven-level cascaded inverter is illustrated in Figure 6. The harmonic spectrum analysis of the output signal is shown in Figure 7. From the simulation results, the undesirable odd harmonics have been canceled totally from the output signal.

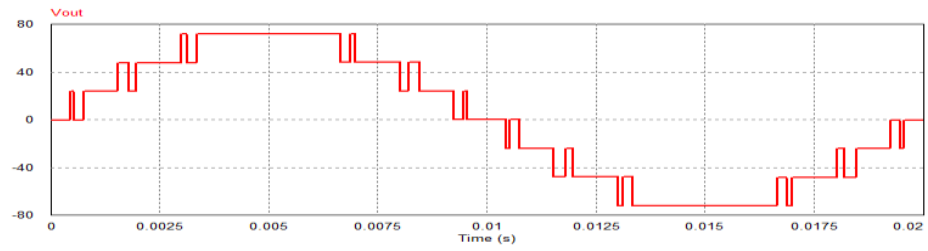

Figure 6. The output voltage of signal phase 7-level inverter before using optimization technique

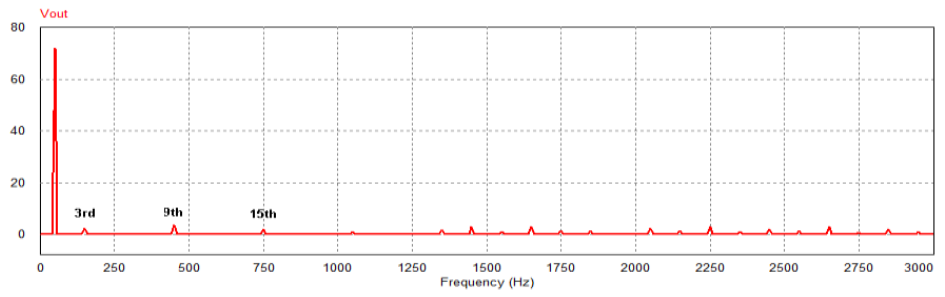

Figure 7. FFT of the output voltage signal using optimum switching angles

Total Harmonic Distortion has been one of the biggest issues in the multilevel inverter. By using the proposed method, THD is reduced further in the second pursuit of elimination technique. This technique can delay the switching angles to new positions by adjusting the duty cycle of the pulses in order to reduce THD and increase the magnitude of the fundamental $(50 \mathrm{~Hz})$ component. The solution of the switching angles at $\mathrm{m}=1.0$ in Table 1 have been delayed by the factor $\Delta \alpha$ (step $0.0001 \mathrm{rad})$. This technique can be in two steps.

\subsection{OHET step one}

In this step, all values of switching angles $\left(\alpha_{1}\right.$ to $\left.\alpha_{9}\right)$ will be subtracted from the value of $\Delta \alpha$ in step 0.0001 radian as in (8). The new result of the switching angles must be under conditions of (3) in the range between 0 to $\pi / 2$ as shown in Figure 8 . 
Figure 9 shows how changing the value of $\Delta \alpha$ on THD in the range from 0 to 0.006 radian with the step 0.0001 radian. The THD has been decreased from $11.49 \%$ to $10.43 \%$ with a difference of $1.06 \%$ and it is achieved a minimum value at $\Delta \alpha=0.0036$.

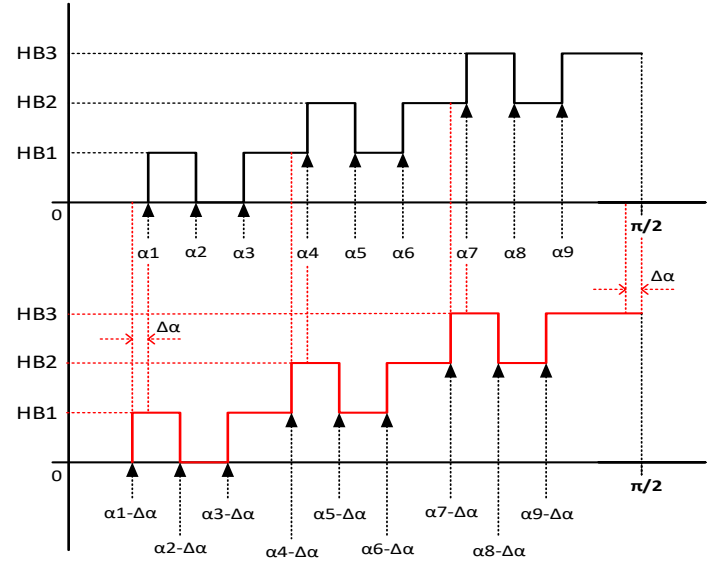

Figure 8. OHET technique in step one for seven-level inverter

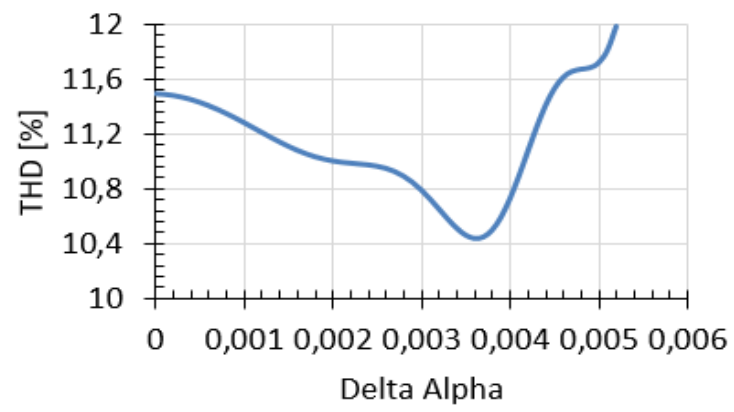

Figure 9. THD against the factor $\Delta \alpha$

\subsection{OHET step two}

For this step, only the switching angles $\alpha_{3}, \alpha_{6}$, and $\alpha_{9}$ will delay twice values of $\Delta \alpha$ as shown in Figure 10. The relation of the switching angles and the factor $\Delta \alpha$ is given by:

$$
\begin{aligned}
& \alpha_{1}=\alpha_{1}-\Delta \alpha \\
& \alpha_{2}=\alpha_{2}-\Delta \alpha \\
& \alpha_{3}=\alpha_{3}-(\Delta \alpha * 2) \\
& \alpha_{4}=\alpha_{4}-\Delta \alpha \\
& \alpha_{5}=\alpha_{5}-\Delta \alpha \\
& \alpha_{6}=\alpha_{6}-(\Delta \alpha * 2) \\
& \alpha_{7}=\alpha_{7}-\Delta \alpha \\
& \alpha_{8}=\alpha_{8}-\Delta \alpha \\
& \alpha_{9}=\alpha_{9}-(\Delta \alpha * 2)
\end{aligned}
$$

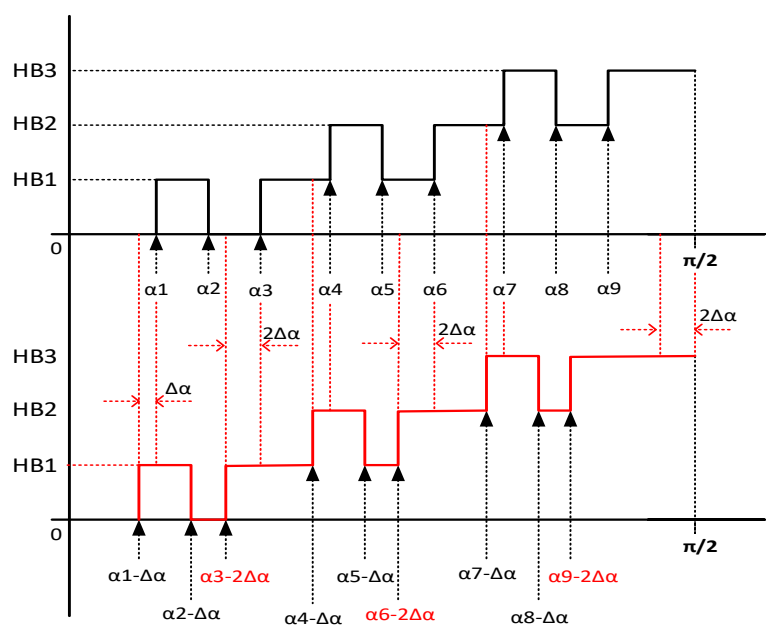

Figure 10. OHET optimization case-two of 7-level inverter 
Figure 11 shows the effect of optimization technique in second step on the THD of seven-level inverter. It can be observed that there has been a decrease of $2.93 \%$ in the THD from $11.49 \%$ to $8.56 \%$. The minimum THD is achieved at $\Delta \alpha=0.0026$ radian. The duty cycle of the second pulses in each $\mathrm{H}$-Bridge control signal is increased by double values of $\Delta \alpha$. The values of the switching angles ( $\alpha_{1}$ to $\left.\alpha_{9}\right)$ for the optimization in step two are presented in Table 2. The new result of switching angles at $\Delta \alpha=0.0026$ is simulated by PSIM softwere and the harmonic spectrum analysis as presented Figure 12.

Table 2. The result of switching angles in case-two at $\Delta \alpha=0.0026$ radians

\begin{tabular}{cccccccccc}
\hline S. angles & $\alpha 1$ & $\alpha 2$ & $\alpha 3$ & $\alpha 4$ & $\alpha 5$ & $\alpha 6$ & $\alpha 7$ & $\alpha 8$ & $\alpha 9$ \\
\hline Degree & 6.0323 & 7.4427 & 9.5938 & 25.5991 & 30.2408 & 31.4829 & 52.0761 & 54.1910 & 56.2558 \\
Radian & 0.1053 & 0.1299 & 0.1674 & 0.4468 & 0.5278 & 0.5495 & 0.9089 & 0.9458 & 0.9818 \\
\hline
\end{tabular}

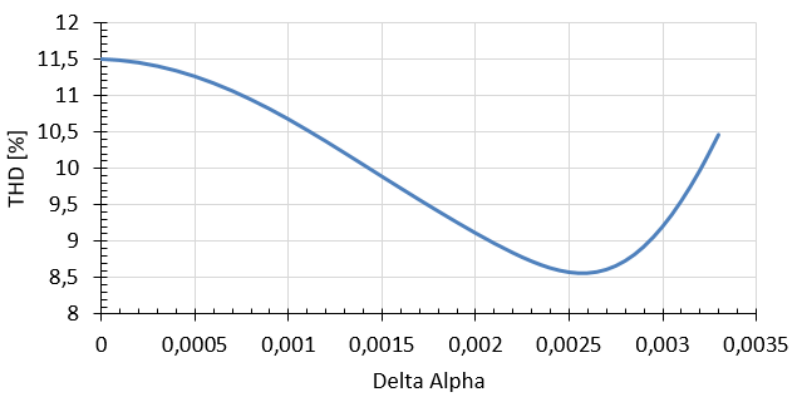

Figure 11. Effect of optimization method in case two on the THD for 7-level inverter

\section{THE EXPERIMENTAL RESULT}

Rigol DS1052z, digital oscilloscope is used to display the experimental results of seven level cascaded multilevel inverter without using a filter circuit. The experimental result of the output voltage waveform and the harmonics spectrum analysis before using the optimization technique is shown in Figure 12. Digital Power Meter model 66202 is used to measure the voltage THD experimentally. THD of the experimental result before using the optimization technique achieved of $13.17 \%$. This results for seven-level cascaded multilevel inverter without using low pass filter.

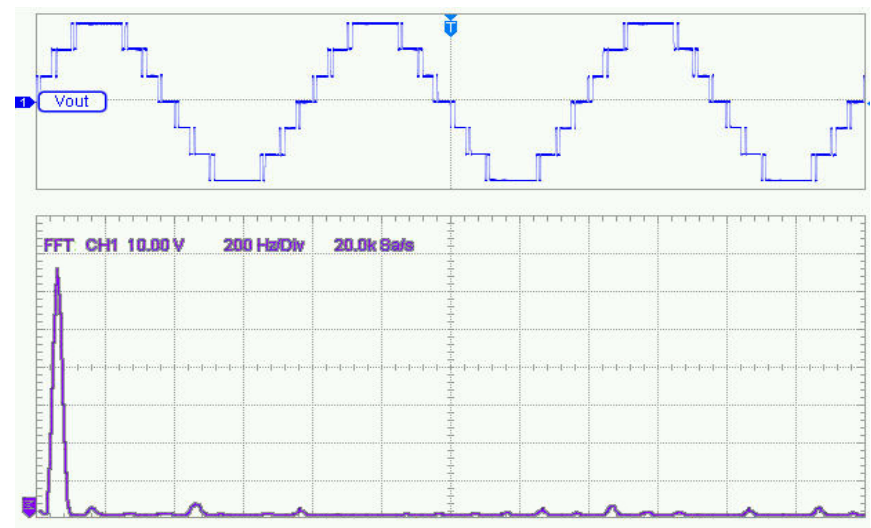

Figure 12. FFT analysis of seven level cascaded inverter before using OHET method

After using the optimization technique, the experimental value of the harmonic spectrum analysis is depicted in Figure 13. Notice from Figure 12 that the selected odd harmonics have been removed from the output signal, also the magnitudes of the triplen harmonics are quite small. The voltage THD value is obtained of $11.16 \%$. 
The experimental results of the THD has been reduced from $13.17 \%$ to $11.16 \%$. with difference of $2.01 \%$. Table 3 illustrates the compersion between theoretical, simulation, and experimental results before and after using the optimization technique.

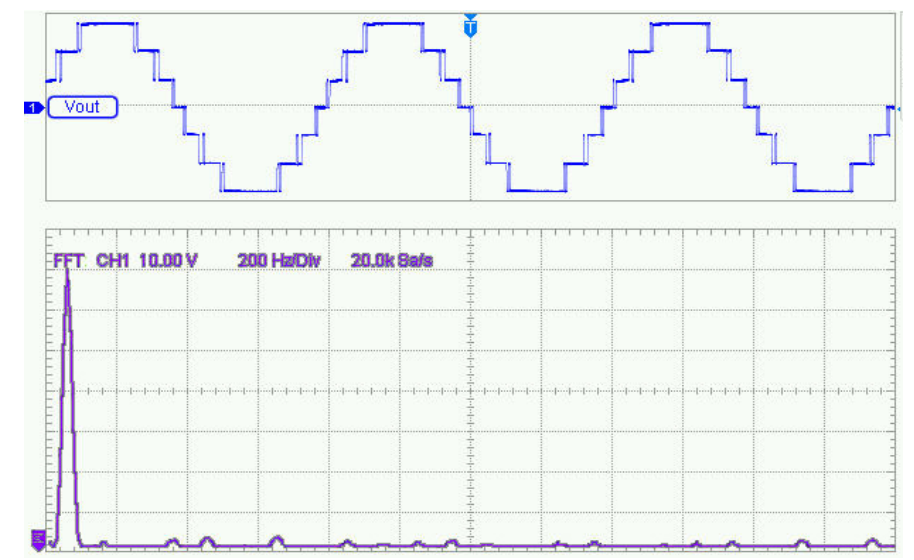

Figure 13. Voltage THD of seven-level inverter after using OHET

Table 3. The performance of the OHET on voltage THD

\begin{tabular}{cccc}
\hline OHET & $\begin{array}{c}\text { THDv [\%] } \\
\text { calculation }\end{array}$ & $\begin{array}{c}\text { THDv [\%] } \\
\text { simulation }\end{array}$ & $\begin{array}{c}\text { THDv [\%] } \\
\text { Experimental }\end{array}$ \\
\hline Before & 11.49 & 15.21 & 13.17 \\
After & 8.56 & 12.90 & 11.16 \\
\hline
\end{tabular}

\section{CONCLUSION}

This paper has proposed a new optimization harmonic elimination method for cascaded multilevel inverter to re-mitigate THD with increased the magnitude of the fundamental component voltage. Hardware prototype of a single-phase seven-level cascaded multilevel inverter has been implemented to verify the theoretical and the simulation results of the proposed technique. From the experimental result, OHET has achieved a reduction of THD from $13.17 \%$ to $11.16 \%$ with $2.01 \%$. The results are verified through simulation and experimental validated by eliminating low-order odd harmonics without using a low pass filter. The simulation and experimental results are in close agreement with almost identical values and shape.

\section{REFERENCES}

[1] S. Alepuz, S. Busquets-Monge, J. Bordonau, J. Gago, D. Gonzalez and J. Balcells, "Interfacing Renewable Energy Sources to the Utility Grid Using a Three-Level Inverter," in IEEE Transactions on Industrial Electronics, vol. 53, no. 5, pp. 1504-1511, Oct. 2006.

[2] Q. Li and P. Wolfs, "A Review of the Single Phase Photovoltaic Module Integrated Converter Topologies With Three Different DC Link Configurations," in IEEE Transactions on Power Electronics, vol. 23, no. 3, pp. 1320-1333, May 2008.

[3] S. B. Kjaer, J. K. Pedersen and F. Blaabjerg, "A review of single-phase grid-connected inverters for photovoltaic modules," in IEEE Transactions on Industry Applications, vol. 41, no. 5, pp. 1292-1306, Sept.-Oct. 2005.

[4] E. H. E. Aboadla, S. Khan, M. H. Habaebi, T. Gunawan, B. A. Hamidah and M. Tohtayong, "Modulation Optimization Effect on Total Harmonic Distortion of Single Phase H-Bridge Inverter Based Selective Harmonics Elimination Technique," 2016 International Conference on Computer and Communication Engineering (ICCCE), Kuala Lumpur, 2016, pp. 200-203.

[5] S. Daher, J. Schmid and F. L. M. Antunes, "Multilevel Inverter Topologies for Stand-Alone PV Systems," in IEEE Transactions on Industrial Electronics, vol. 55, no. 7, pp. 2703-2712, July 2008.

[6] E. Villanueva, P. Correa, J. Rodriguez and M. Pacas, "Control of a Single-Phase Cascaded H-Bridge Multilevel Inverter for Grid-Connected Photovoltaic Systems," in IEEE Transactions on Industrial Electronics, vol. 56, no. 11, pp. 4399-4406, Nov. 2009.

[7] M. Aleenejad, H. Mahmoudi and R. Ahmadi, "Multifault Tolerance Strategy for Three-Phase Multilevel Converters Based on a Half-Wave Symmetrical Selective Harmonic Elimination Technique," in IEEE Transactions on Power Electronics, vol. 32, no. 10, pp. 7980-7989, Oct. 2017.

[8] J. Rodriguez, Jih-Sheng Lai and Fang Zheng Peng, "Multilevel inverters: a survey of topologies, controls, and 
applications," in IEEE Transactions on Industrial Electronics, vol. 49, no. 4, pp. 724-738, Aug. 2002.

[9] Y. Yu, G. Konstantinou, B. Hredzak and V. G. Agelidis, "Operation of Cascaded H-Bridge Multilevel Converters for Large-Scale Photovoltaic Power Plants Under Bridge Failures," in IEEE Transactions on Industrial Electronics, vol. 62, no. 11, pp. 7228-7236, Nov. 2015.

[10] X. Sun, B. Wang, Y. Zhou, W. Wang, H. Du and Z. Lu, "A Single DC Source Cascaded Seven-Level Inverter Integrating Switched-Capacitor Techniques," in IEEE Transactions on Industrial Electronics, vol. 63, no. 11, pp. 7184-7194, Nov. 2016.

[11] E. H. E. Aboadla, K. A. Aznan, M. Tohtayong, S. Khan, M. A. Hannan and M. N. Uddin, "Low spikes and low harmonic distortion multilevel inverter for induction motor implementation," 2017 IEEE Industry Applications Society Annual Meeting, Cincinnati, OH, 2017, pp. 1-7.

[12] K. Ganesan, K. Barathi, P. Chandrasekar, and D. Balaji, "Selective Harmonic Elimination of Cascaded Multilevel Inverter using BAT algorithm," Procedia Technol., vol. 21, pp. 651-657, 2015.

[13] E. H. E. Aboadla, S. Khan, M. H. Habaebi, T. Gunawan, B. A. Hamidah and M. Tohtayong, "Selective Harmonics Elimination technique in single phase unipolar H-bridge inverter," 2016 IEEE Student Conference on Research and Development (SCOReD), Kuala Lumpur, 2016, pp. 1-4.

[14] E. H. E. Aboadla, S. Khan, M. H. Habaebi, T. Gunawan, B. A. Hamidah and M. B. Yaacob, "Effect of modulation index of pulse width modulation inverter on Total Harmonic Distortion for Sinusoidal," 2016 International Conference on Intelligent Systems Engineering (ICISE), Islamabad, 2016, pp. 192-196.

[15] N. V. Kumar, V. K. Chinnaiyan, M. Pradish and M. S. Divekar, "Selective harmonic elimination: An comparative analysis for seven level inverter," 2016 IEEE Students' Technology Symposium (TechSym), Kharagpur, 2016, pp. 157-162.

[16] A. B. Basri, N. A. Zaidi, N. B. Bopi, E. H. Aboadla, S. Khan, and M. H. Habaebi, "Effects Of Switching Frequency To Series Loaded Series Resonant Circuit," ARPN J. Eng. Appl. Sci., vol. 11, no. 1, pp. 382-386, 2016.

[17] M. Ahmed, E. Hendawi, and I. B. M. Taha, "Simple analytical solution for selective harmonic elimination technique," Electron. Lett., vol. 52, no. 9, pp. 1-2, 2016.

[18] H. Zhao, T. Jin, S. Wang and L. Sun, "A Real-Time Selective Harmonic Elimination Based on a Transient-Free Inner Closed-Loop Control for Cascaded Multilevel Inverters," in IEEE Transactions on Power Electronics, vol. 31, no. 2, pp. 1000-1014, Feb. 2016.

[19] E. H. Aboadla et al., "Effect of Duty Cycle on THD for Multilevel Inverter Based on Selective Harmonic Elimination Technique," 2018 7th International Conference on Computer and Communication Engineering (ICCCE), Kuala Lumpur, 2018, pp. 56-61.

[20] A. Masaoud, H. W. Ping, S. Mekhilef and A. S. Taallah, "New Three-Phase Multilevel Inverter With Reduced Number of Power Electronic Components," in IEEE Transactions on Power Electronics, vol. 29, no. 11, pp. 60186029, Nov. 2014.

[21] M. Malinowski, K. Gopakumar, J. Rodriguez and M. A. Perez, "A Survey on Cascaded Multilevel Inverters," in IEEE Transactions on Industrial Electronics, vol. 57, no. 7, pp. 2197-2206, July 2010.

[22] R. Gupta, S. Member, A. Ghosh, and A. Joshi, "Switching Characterization of Cascaded," in IEEE Trans. Ind. Electron., vol. 55, no. 3, pp. 1047-1058, 2008.

[23] S. G. Song, F. S. Kang, and S. Park, "Cascaded Multilevel Inverter Employing Three-Phase Transformers and Single DC Input," in IEEE Trans. Ind. Electron., vol. 56, no. 6, pp. 2005-2014, June 2009.

[24] W. Fei, B. Wu and Y. Huang, "Half-wave symmetry selective harmonic elimination method for multilevel voltage source inverters," in IET Power Electronics, vol. 4, no. 3, pp. 342-351, March 2011.

[25] J. Napoles et al., "Selective Harmonic Mitigation Technique for Cascaded H-Bridge Converters With Nonequal DC Link Voltages," in IEEE Transactions on Industrial Electronics, vol. 60, no. 5, pp. 1963-1971, May 2013.

[26] H. Lou, C. Mao, D. Wang, J. Lu and L. Wang, "Fundamental modulation strategy with selective harmonic elimination for multilevel inverters," in IET Power Electronics, vol. 7, no. 8, pp. 2173-2181, August 2014.

[27] B. Ozpineci, L. M. Tolbert and J. N. Chiasson, "Harmonic optimization of multilevel converters using genetic algorithms," in IEEE Power Electronics Letters, vol. 3, no. 3, pp. 92-95, Sept. 2005.

[28] N. Abd, H. Wooi, and J. Selvaraj, "The 3 rd International Conference on Sustainable Future for Human Security Elimination of harmonics in photovoltaic seven-level inverter with Newton-Raphson optimization," Procedia Environ. Sci., vol. 17, pp. 519-528, 2013.

[29] C. R. S. Reinoso, M. De Paula, D. H. Milone, and R. H. Buitrago, "Photovoltaic Inverters Optimisation," Energy Procedia, vol. 14, no. 2011, pp. 1484-1489, 2012.

[30] M. S. A. Dahidah and V. G. Agelidis, "Selective Harmonic Elimination PWM Control for Cascaded Multilevel Voltage Source Converters: A Generalized Formula," in IEEE Transactions on Power Electronics, vol. 23, no. 4, pp. 1620-1630, July 2008.

[31] S.Y. Sim, C.K. Chia, W.M. Utomo, H.H. Goh, Y.M.Y. Buswig, A.J.M.S. Lim, S.L. Kek, A.A. Bohari, C.L, Cham, "Enhance Cascaded H-Bridge Multilevel Inverter with Artificial Intelligence Control," Indonesian Journal of Electrical Engineering and Computer Science (IJEECS), 11(1), pp. 105-112, 2018. 